\title{
A FRANÇA NO LIMIAR DE NOVOS TEMPOS: PAUL VIDAL DE LA BLACHE E A REGIONALIZAÇÃo *
}

\author{
Marie-Vic Ozouf-Marignier \\ Centre de Recherches Historiques, EHESS
}

\author{
Marie-Claire Robic \\ Epistémologie et Histoire de la Géographie (EHGO), CNRS \\ Universidade de Paris I
}

Exercido diretamente sobre o departamento, o poderio do Estado é um contrasenso na vida moderna. Frente a um formalismo administrativo, para quem toda iniciativa regional é uma usurpação, ele ergue um espírito chauvinista que sujeita tudo à sua medida. Não é mais o tempo de procurar na centralização política o segredo da força. Significaria ser muito previdente substituir um mecanismo tenso e rígido por um organismo mais elástico que emprestasse à vida algo da força de resistência que ela concede a todas as suas criações. (VIDAL DE LA BLACHE, 1910)

Tentaremos mostrar aqui que Paul Vidal de la Blache foi um dos mais determinados promotores de uma regionalização dos Estados do século $\mathrm{XX}$, o que o assegura nos quadros da atividade e da representação política à medida das dimensões do mundo moderno. $\mathrm{O}$ que está em jogo é a adaptação à modernidade, esta se caracterizando pela dominação da economia e pela

\footnotetext{
* Este trabalho repousa também sobre uma pesquisa coletiva da equipe Epistemologia e História da Geografia (URA 1243) do CNRS-Université de Paris I sobre o Tableau de la géographie de la France no ano de 1996. Publicado originalmente em L'Information Géographique, vol. 59. 1995. Tradução : Guilherme Ribeiro. Revisão Técnica : Rogério Haesbaert. O tradutor agradece às autoras e também a Yannick Gäel a gentileza no esclarecimento para a tradução de algumas passagens.
} 
mundialização. Sua reflexão como geógrafo versa sobre as dimensões dos agrupamentos úteis, o papel diretor das metrópoles urbanas, a função econômica das divisões modernas e a necessária integração entre as regiões de um mesmo território nacional. Contudo, quando apresentamos Vidal como fundador das monografias regionais da Escola francesa de geografia, sua defesa da "região geográfica" o situa em uma outra acepção da região, aquela de uma entidade paisagística ou de uma entidade social e natural. Não obstante, também, rótulos de "passadista" e "ruralista" são comumente associados ao nome de Vidal de la Blache. Apresentamo-lo como o defensor do "pays", pequena unidade testemunha de uma harmonia secular entre os homens e a natureza, ao modo da região geográfica, mas à escala local. Ou bem ainda dramatizamos seu itinerário, distinguindo dois Vidal: o tradicionalista defensor do local e da ligação com o solo; e o modernista, ordenador do território e mesmo um geopolítico. É necessário escolher entre estas representações contraditórias? Ou, antes, sublinhar as flutuações, os ritmos distribuídos segundo os contextos de suas intervenções? Distinguir as posições?

Recuperemos o dossiê. Lembremos de início o teor dos documentos que concorreram a este processo de recorte regional: qual é a função principal da proposta, como é legitimado o agrupamento proposto e quais são as características estruturais das malhas concebidas ou ressaltadas? Sublinhar-se-á a transição entre o recorte naturalista e o recorte político-econômico. Em seguida, examinaremos as lógicas das posições que testemunham os engajamentos de pedagogo, de cientista e de expert político nos quais se inscrevem os projetos vidalianos. Por fim, convidaremos a refletir, na perspectiva da sociologia do conhecimento, as origens dos deslocamentos entre a representação modernista que demos a Vidal e as outras imagens que lhe são conferidas.

\section{Oito peças de persuasão}

Uma dezena de artigos e obras consagradas às divisões regionais ou aos recortes espaciais, cujos princípios são mais ou menos justificados, podem sustentar a análise do que Vidal propôs ou preconizou em matéria do recorte regional do espaço. Retenhamos as oito principais:

1888: O artigo Des divisions fondamentales du sol français ("As divisões fundamentais do solo francês" ${ }^{1}$ ), retomado no início do século como introdução a um manual consagrado primeiramente à França, é escrito sem dificuldade, numa perspectiva pedagógica. São as linhas diretrizes dadas pelo mestre. Segundo Vidal,

\footnotetext{
1. Este texto encontra-se traduzido em espanhol sob o título "Las divisiones fundamentales del territorio frances" em Mendoza, J. (1982) "El pensamiento geográfico". Barcelona: Alianza Editorial. (N.T.)
} 
A França no limiar de novos tempos: Paul Vidal de La Blache e a Regionalização

o ensino de Geografia deve ser feito nos quadros regionais, a fim de não dissociar o que a natureza reúne. Este princípio está fundado sobre a natureza mesma da Geografia, tal como a estabeleceu Carl Ritter.

Em uma abordagem didática e apoiando-se no caso francês (considerado particularmente convincente), Vidal rejeita o uso do departamento e dos pequenos pays como quadros de estudo. Ele prefere as áreas mais vastas, que realçam a categoria "região natural". São os conjuntos próximos das grandes unidades geológicas, bem evidentes na França e, mais geralmente, de uma zona climática homogênea, disso que constitui suas regiões naturais, uma combinação ligando as condições naturais (solo, vegetação, etc.) e sua valorização pelos grupos humanos.

O pays é uma boa representação da categoria região natural que retém a sua atenção de geógrafo. Ele pretende ser sugestivo para os jovens estudantes, dada sua proximidade da experiência popular. Mas o pays é eliminado da didática da Geografia por uma razão pouco explícita, onde entra em jogo um inconveniente: a multidão de pays, excesso que prejudica o despertar do raciocínio que é buscado; dificuldade de seu reconhecimento: incerteza sobre seus limites e ausência de um mapa exaustivo. Igualmente são descartados o quadro departamental e a província histórica, esta sendo muito dependente das eventualidades históricas.

O recorte da França é apenas esboçado, e pode ser enunciado em cinco grandes conjuntos: a Bacia de Paris, o Planalto Central, o Oeste, o Midi, o Vale do Ródano e do Saône. O restante é constituído por "grupos regionais periféricos", "taludes ao longo de nossas fronteiras" que Vidal não detalha.

As regiões são formas plenas e não somente o teatro vivo da história. Os limites são assinalados com uma certa atenção, menos em seus detalhes do que como lugares de contatos, e pelos sítios de estabelecimento urbano.

1903: Tableau de la géographie de la France ("Quadro" ou "Panorama da geografia da França"), abertura de uma coleção de história da França das origens à Revolução. Destinada ao grande público culto e dirigida pelo historiador Ernest Lavisse, é uma obra de edificação nacional e republicana. Ela une à representação científica a expressividade da descrição, além de, especialmente em sua edição ilustrada, o testemunho iconográfico (mapa e fotografia). Para Vidal, trata-se de demonstrar a existência de uma individualidade geográfica.

O livro em questão é um tríptico ${ }^{2}$. A primeira folha ${ }^{3}$ pinta a França como uma unidade fundada sobre a diversidade ou, antes, como uma unidade ligada a uma estrutura espacial particular: os contrastes naturais estão presentes em qualquer escala. A terceira pensa a dimensão espaço-temporal: a relação passado-presentefuturo, ligada às virtualidades dos recursos locais, à centralização política e às

2. Quadro pintado em três tábuas. (N.T.)

3. Folha de um triptico, "volet", no original. (N.T.) 
redes de transportes. As fronteiras não são traçadas em seu conjunto, são apenas evocadas. A parte central, a maior, descreve o território através de um encaixe de unidades espaciais. As grandes divisões do livro são: a França do Norte (Ardennes e Flandres, Bacia parisiense, Região renana); Entre os Alpes e o oceano (o Sillon do Saône e do Ródano, o Maciço Central); o Oeste (no qual: a Bretanha e seus confins); e o Midi (Midi mediterrâneo, Midi dos Pireneus, Midi oceânico) (carta 1, estabelecida após a retirada da parte descritiva).

O Tableau é uma abordagem de Geografia Política, pois se trata de apresentar uma nação em seu território. A lógica do recorte, se seguimos as explicitações, a ordem da descrição e as valorizações das diversas partes, está fundada sobre a análise da formação territorial a partir da expansão dos Capetos. O Norte, depois a bacia parisiense, abrem o quadro, pois é aí que, na adversidade frente aos germanismos, é fundado o centro de um poderio conquistador. O Sul, submisso, é particularmente negligenciado.

A referência aos pequenos pays é frequiente, mas desigual. A cor local tornase onipresente pela descrição paisagística detalhada e pelo uso da terminologia vernacular. Os departamentos estão ausentes e a alusão às províncias e a diversas entidades políticas antigas integra-se numa análise contínua (senão sistemática) dos tipos de agrupamentos sociopolíticos - do pequeno pays autônomo vivendo autarquicamente, como no Val jurassiano, à província, e mesmo ao Estado (a Normandia) e à vasta "região política" que representa o Estado-Nação francês na Europa.

O jogo do tríptico e os encaixes da apresentação em livros, capítulos e parágrafos constróem algo diferente do que um mosaico de pays. O território apresentado é mostrado como uma hierarquia de conjuntos que foram espacializados historicamente por uma política contínua de aquisições, anexações e produção de lugares notáveis [haut-lieux] dos poderes eclesiástico e real. Tais conjuntos são, por conseguinte, encaixados e qualificados — na verdade, hierarquizados — por sua natureza política. Freqüentemente, seus limites são demarcáveis, mas nem sempre. Para delimitar as entidades, o argumento geológico domina amplamente, mas não é o único. As descrições começam pela base geológica. O interesse concedido às articulações entre regiões de nível superior ("passagens", "anexos" do território, "nós", lugares notáveis [haut-lieux]) e a natureza das redes de circulação completa a visão do recorte.

1904: Les pays de la France ("Os pays da França"), conferência proferida na Sociedade de Economia Social, de inspiração leplaysiana (reformista tradicionalista), é seguidamente citada como a prova por excelência do "passadismo" de Vidal. Um fenômeno pode explicar porquê esse texto é tão conhecido: ele é um dos raros artigos ou conferências de Vidal que figuram à parte no catálogo da Biblioteca Nacional. Vidal trata efetivamente dos pequenos pays 
compreendidos em sua dupla natureza: natural e social. A partir de uma apresentação de fotografias, ele mostra sua variedade na França contemporânea. Seu comentário os organiza em função da diversidade do povoamento e das paisagens. Ele conclui em prol da fecundidade da démarche monográfica que é, como sabemos, a de Le Play.

1909: $\mathrm{O}$ artigo Régions naturelles et noms de pays ("Regiões naturais $\mathrm{e}$ nomes de pays") apresenta à Academia de Ciências Morais e Políticas a obra de Lucien Gallois. Mostrando todas as dificuldades de interpretação dos nomes dos pays, Vidal, com Gallois, opõe a significação local — ou mesmo estritamente camponesa -, que se deve conceder à noção de pays, ao valor do conceito científico adquirido pela região natural. O que é específico da região natural do geógrafo é combinar muitas áreas de extensão de fenômenos parciais, combinação que se manifesta por uma "fisionomia" particular da superfície terrestre. Pays e regiões apontam, portanto, para duas lógicas diferentes: a lógica popular e a lógica científica, mas eles tem em comum a designação das individualidades, "grupos naturais nos quais entra um elemento humano". Esta conivência entre natureza e sociedade é, contudo, discutida por Vidal. Até onde podemos fazê-la de guia para uso na reflexão política? Vidal sugere que as questões de redivisão política carecem de um conselho geográfico. Ele insiste sobre a descontinuidade entre o princípio local de ligação com o solo e o princípio da dependência horizontal que governa a troca econômica ou a organização política. Mas se a cidade possui o papel motor e crescente neste domínio e se o pays tende, por conseguinte, a não ser mais que um laço tradicional, ele preserva um sentido.

1910: O artigo consagrado às Régions françaises ("Regiōes francesas"), proposição de um recorte regional da França na perspectiva de uma descentralização política, acompanhada de um mapa, responde a uma solicitação vinda do Presidente do Conselho, Aristide Briand. Vidal demonstra que, se a França quer salvaguardar sua posição na concorrência mundial, deve adotar uma nova estrutura. Diferente do clássico departamento e também da província do Antigo Regime, a região econômica se impôs. A conjunção da retração do espaço-tempo e das condições da produção do século XIX produziram uma sensível ruptura histórica nas últimas três décadas. A esta revolução deve corresponder uma nova forma de organização territorial. No seio deste projeto, uma região de um novo tipo, que muda de escala e que deve ser animada por uma metrópole, a "cidade regional". Vidal forja, então, um novo conceito: o de "nodalidade".

Seu argumento repousa sobre a observação de uma tendência espontânea ao agrupamento no domínio da produção e das trocas e sobre a análise dá descontinuidade que representa a civilização industrial: mudança de escala e mecanismos de integração, concentração e mobilidade. Daí resulta o diagnóstico 
de uma necessária adaptação: "O que há de saudável e de vivificante nesta forma considerada um tanto quanto brutal de civilização é o princípio de esforço, a solidificação perpétua de progresso. (...) Mas é necessário uma armadura cômoda e flexível ao campeão que quer permanecer na luta". Um estudo regional da França e suas transformações em curso permite esboçar as formas de organização desejáveis (texto 1 do anexo a este artigo). Um mapa das 17 regiões reagrupando departamentos inteiros (salvo exceções) acompanha o documento. Suas capitais são mencionadas, e não o nome das regiões. $O$ traçado dos rios é excepcionalmente reforçado (mapa 2).

Seguindo as articulações da análise espacial, vemos desenhar-se uma divisão entre a França ativa ao norte da linha Sète-Marseille/Le Havre, a França nãometropolizada do oeste e do sudoeste, e uma grande bacia de Paris, organizável em auréolas e em pólos portuários e interiores. Podemos notar que Vidal descreveu a divisão da França em duas partes, separadas pela "linha Cette-Le Havre" no mapa de seu Atlas Générale (1895) consagrado à indústria. Ele irá retomá-la em La France de l'Est, sublinhando novamente esta dualidade.

Em resumo, a esta altura dois imperativos se impõem face à concorrência internacional: a organização interna da França pelo desenvolvimento de regiões especializadas, centradas sobre uma metrópole urbana, bem interconectadas, e a organização específica da interface entre a França e o mundo - notadamente pelas zonas costeiras, intermediárias entre o mercado francês e o "grande mercado, inesgotável, fecundo em promessas de futuro", aberto pelo Oceano.

1911: La relativité des divisions régionales ("A relatividade das divisões regionais") é uma conferência abrindo uma série de intervenções destinadas a esclarecer a opinião culta sobre a questão regional. A tese é que, desde que saíram de um estágio inicial, as regiões naturais não são os quadros fixos da organização social. A argumentação está centrada em torno da evolução dos quadros de ação coletiva, resultantes das modalidades de intercâmbio (texto 2 em anexo). Vidal sublinha o papel das cidades na passagem de um mosaico de pays homogêneos às províncias que os solidarizam. Por um lado, não existe mais isolamento depois da revolução dos transportes; por outro, produzem-se novos fenômenos de "concentração", tais como a metropolização (concentração demográfica em determinadas grandes cidades e incremento de seu papel) e as concentrações urbanas e econômicas (regiões de cidades ou de portos) rompendo com a regularidade dos espaçamentos e das antigas dimensões territoriais - como os departamentos. Assim, o conceito de nodalidade se tornou preciso. As consequências sobre uma necessária reforma territorial da França são evocadas (com o exemplo típico de uma nova região econômica: a região lionesa).

1917a: La rénovation de la vie regional (“A renovação da vida regional”), 
título de uma conferência proferida, durante a guerra, diante da associação Fé e Vida, deve ser compreendida como um apelo a uma retomada da França pelo desenvolvimento da região. Evidentemente, dizia Vidal, o papel excessivo da capital foi reduzido pelo renascimento provincial, mas a idéia cultural e a nostalgia do passado que acompanharam esta renovação não são mais a solução face aos desafios contemporâneos. A melhor resposta ao risco de decadência consiste em uma adaptação da vida econômica. $\mathrm{O}$ agrupamento regional dos interesses se impõe, pela sua organização, sob a égide de uma capital regional, onde bancos, indústrias e universidades podem concorrer para o desenvolvimento, com amplo conhecimento dos homens e dos recursos. Modernização, mas não futurismo: velhos países cujas histórias não conheceram rupturas, a França não seria como aqueles países de civilização decadente, como a Itália ou a Grécia.

1917b: La França de l'Est ("A França do Leste") constitui um ensaio de Geografia regional, analisando um front geopolítico conflituoso no momento da própria redação do livro. Segundo Vidal, a Alsácia-Lorena é um grande espaço político que foi integrado há muito tempo à nação francesa, de acordo com um modelo de adesão pacífica, oposto ao sistema coercitivo alemão. De início, é apresentado o quadro natural. O quadro histórico analisa esta incorporação suave. Em seguida é mostrado o papel específico da região como intermediária entre a Europa Ocidental e a Europa Central. Adiante, Vidal detalha a vida econômica e a organização interna, dominadas pela existência de regiões industriais têxteis, do carvão e do ferro, e por sua estruturação em regiões econômicas modernas sob o domínio das grandes cidades. A reunificação deste grande espaço e sua incorporação à França Maior (metrópole e império colonial) trará novos problemas de adaptação.

\section{Do Naturalismo ao Economismo: uma Lenta Deriva}

Comparando essas oito posições sobre o tema dos recortes regionais, é necessário admitir uma forte variação nos princípios e nas divisões adotadas. Por uma lenta deriva, vemos um modelo naturalista sendo erodido frente à onipresença da análise econômica: Vidal passa da "região natural" à "região econômica" (texto 3 em anexo).

Notadamente, podemos sublinhar a inspiração marcadamente naturalista que domina os primeiros textos (1888, 1903 e 1904). Podemos denominá-la legado de Elie de Beaumont, nome do geólogo que traçou o mapa geológico da França em pequena escala em 1841 e que mostrou a harmonia do território conferindo-o uma forma densa: o "oito" que as camadas jurássicas constituem em torno da bacia parisiense e do "platô" ou "maciço" central. Este anel cobre um "pólo negativo" e um "pólo positivo", representado pela bacia parisiense, a força atrativa do espaço francês. As explicações são mais difíceis em 1909, e um deslocamento na esfera 
econômica e da interação à distância fixou-se em 1910 e se confirmou nas proposições seguintes. A reflexão sobre a região natural se esvai. Os artigos mais tardios e o livro dedicado a La France de l'Est consagram a região econômica como uma nova entidade, fundada sobre um feixe de atividades agrícolas ou industriais especializadas e sobre sua organização por uma metrópole.

Através destes textos, podemos ler também a propensão que tem Vidal em confirmar seu interesse pelos recortes em grandes malhas e por uma reflexão sobre o papel da cidade e da circulação na organização do mundo moderno. Grosso modo, o recorte regional volta a selecionar as metrópoles. Primeiramente, a centralidade urbana tem importância. O limite regional é concebido como vago, flutuante, eventualmente construído como limite entre dois campos de influência ou de concorrência urbana. Exposta por Juillard em 1962, a região funcional já estava bem colocada a partir de 1909. Ela figurava através do exemplo tópico da região lionesa no Tableau.

Todos estes artigos conferem um alcance positivo ao fato urbano. Cada vez mais, o lugar do econômico se impõe. Vidal afirma frequientemente que, de todas as ligações, os interesses econômicos são os que melhor cimentam as formações políticas. Dois corolários figuram a partir do início do século: em uma perspectiva sincrônica, o desafio da integração mundial e, em uma perspectiva diacrônica, a análise da relatividade das divisões regionais.

Ao mesmo tempo que o pequeno pays está menos presente, seu caráter recessivo (do ponto de vista das leis da evolução), obsoleto ou anacrônico em relação ao progresso, é afirmado. À nostalgia que marca inúmeras páginas do Tableau ou intervenções como Les pays de la France são substituídas por julgamentos cínicos sobre as "folhas murchas e mortas" que no outono só podem cair (1911). Uma hierarquia de valor dos agrupamentos, do pequeno pays autárquico à região moderna, é claramente indicada. Mas a referência ao sentido de enraizamento da experiência humana no lugar jamais desaparece por completo.

Vidal repousa sua análise sobre a experiência francesa. Mas ela não é apresentada como absoluta. Em primeiro lugar, ela é estudada como típica de um espaço médio situado em uma zona climática homogênea (1888). No Tableau, constitui um condensado da Europa e, até mesmo, do mundo: entre os países europeus, a França é um país onde o enraizamento antropológico no solo foi um elemento fundador e que permanece significativo; como no mundo inteiro, ela foi tocada por uma revolução dos transportes perceptível a partir das três últimas décadas do século XIX (1903). Depois, as referências à França estão ligadas, sobretudo, ao grupo do Velho mundo, em relação aos países novos, onde se experimenta diretamente o futuro. O sentido do tempo é dado: antes de tudo, é, a França de amanhã que importa a Vidal, incluído nisso o Tableau, que é visto na nostalgia, mas onde as regiões são qualificadas notadamente através de sua relação com o mundo contemporâneo. Em vista de sua natureza de velha civilização sem 
ruptura, a França deve ser reformista e não revolucionária (1917a). Com La France de l'Est, o desafio europeu torna-se fundamental e a escala de referência ainda é mundial, mas o centro de gravidade se desloca em direção à América e ao Pacífico.

Paralelamente, notaremos o aprofundamento de certas noções, tais como a de "rede" de cidades ou de comunicações, de calibragem regional e a de "cidade regional". Noção ou mesmo conceito de nodalidade (textos 2, 3 e 4 em anexo e quadro abaixo) e de concentração. Uma reflexão sobre a retração do espaçotempo e sobre a transformação do espaçamento ${ }^{4} \mathrm{e}$ das dimensões úteis à vida coletiva é tratada de maneira recorrente, e se organiza em teoria dos espaçamentos.

\section{Vidal de la Blache e o conceito de nodalidade}

O termo "nodalidade" é creditado ao geógrafo britânico Mackinder, mas aqui o conceito é distinto. Ao invés de ser uma noção "encruzilhada" [carrefour], quantitativamente mensurável, como em Mackinder, ou um princípio de "centralidade" ao modo da teoria dos lugares centrais, a nodalidade vidaliana é um princípio multiplicativo, suscetível de provocar emergências. As funções de produção, informação e decisão, reunidos localmente na cidade regional ou na cidade industrial, conferem ao lugar nodal uma função de desenvolvimento econômico e enquadramento territorial. Em relação à conexidade da organização em rede evocada hoje, prevalecia a contigüidade.

Nodalidade é também um conceito na medida em que se inscreve no esboço de uma teoria dos agrupamentos humanos, uma teoria evolutiva mostrando como estes agrupamentos passam por estágios ligados à tecnologia dos transportes. Uma reflexão sobre a relatividade do espaço-tempo, relatividade ligada à evolução tecnológica encontra-se assim no fundamento desta teoria. Parece que ele está a ponto de completar o efeito da redução da distância por aquele da incorporação da ciência na produção (em sentido amplo, podemos falar de revolução industrial, e não somente de revolução dos transportes).

Como os princípios mudam, o tratamento das regiões se modifica. As peças de uma França pedagogicamente elaborada ${ }^{5}$ ( 1888 ) são como formas substanciais: são "solos", ao mesmo tempo suporte de circulações e de gêneros de vida (embora esta noção não seja problematizada antes da primeira década do século). Os limites

\footnotetext{
4 "Espacement", no original (N.T.).

5 "Pedagogisée", no original (N.T.).
} 
são então estudados como lugares de contato e neles sítios urbanos ou passagens mais ou menos favoráveis à mistura. No Tableau, o tratamento é complexo (é verdade que, desta vez, trata-se de um livro): devemos entrar pelas leituras segundo diferentes níveis de análise ${ }^{6}$, seguir às vezes itinerários de viajante, compreender as estruturações antigas dos espaços políticos e abordar a organização de regiões nodais modernas, como a região lionesa. O centro é o símbolo essencial da região do século XX: o espaço regional é uma área de irradiação de limites móveis, um espaço de atividades econômicas ligadas em feixe pela cidade. A interconexão torna-se cada vez mais essencial.

Enfim, a terminologia também muda: o termo "política" tende a dar lugar ao "econômico" e ao "humano". Do mesmo modo, na virada do século, o grupo vidaliano centrado em torno dos Annales de géographie substitui "geografia humana" por "geografia política", justificando esta mutação pelo pertencimento da geografia humana à geografia biológica. O vocabulário do Tableau ainda é misto: Vidal fala tanto da geografia política quanto da geografia humana da França. Cada vez mais, sendo um saint-simoniano, ele afirma firmemente que o econômico domina as relações humanas. Sobre este plano, La France de l'Est manifesta uma reviravolta, já que mostra como a adesão voluntária à nação francesa foi o fermento da unidade da França do Leste e como a Revolução de 1789 foi decisiva - Revolução que, até então, como geógrafo, Vidal ignorava, para se concentrar sobre a revolução dos transportes.

\section{Sistemas de Posições: o Professor, o Intelectual, o Homem Público}

As formas de regionalização propostas por Vidal de la Blache durante os trinta anos da Terceira República não poderiam ser avaliadas sem estarem referidas aos três campos de práticas que lhes conferem sentido: o da escola, o das ciências sociais e o da política. Eles são distintos, mas fortemente ligados. Sua estrutura evoluiu um pouco, com ritmos e permanências diferentes. Não poderemos aqui detalhar as histórias da geografia escolar, da institucionalização das ciências sociais, do debate político. Igualmente, o status de Vidal mudou. Professor da Universidade republicana, personagem importante entre os intelectuais cuja figura emerge no momento do Caso Dreyfus, Vidal foi - simplificando - primeiro, um pedagogo, depois um cientista para, enfim, tornar-se um homem público. Seus desafios foram então deslocados, mas permanecendo sempre ligados. Aqui, insistiremos sobre as relações estabelecidas entre estes domínios, através do arranjo entre as preocupações regionais do geógrafo e o movimento multiforme do regionalismo que se difunde no final do século XIX. Feito isto, deixaremos de lado o debate que opôs geógrafos e sociólogos quanto ao caminho mais adequado para uma reforma

\footnotetext{
"lectures en poupée gigognes", no original, referindo-se a bonecas que carregam outras no seu interior, como bonecas russas. (N.T.)
} 
morfológica da nação: para Vidal, a regionalização; para Durkheim, a organização profissional.

\section{Divisões Naturais e Divisões Administrativas}

No domínio da Geografia escolar, Vidal participa de chofre à promoção da Geografia que acompanha o espírito de Revanche. Sua posição é clara: ele se detém numa geografia corográfica, ensinada pelos quadros regionais e não à maneira da geografia sistemática ou de gavetas preconizada pela reforma Levasseur. Como todos seus contemporâneos, sabemos que Vidal rejeita a bacia hidrográfica, bem como a "geografia local", cara a uma constelação de professores que militavam para que as crianças reconhecessem primeiro sua pequena pátria ou bem, em uma perspectiva de pedagogia ativa, seu ambiente próximo. Mas sabemos menos ainda que, promovendo a região natural, Vidal participa, com os outros partidários de uma geografia renovada, da promoção de uma geografia naturalista, em ruptura com a geografia departamental que foi difundida depois da Revolução.

O mesmo período é marcado pelo aumento das aspirações descentralizadoras. Nascidas com a queda do Império, elas não cessaram de se desenvolver, no Congresso e na província. O reencontro destes dois movimentos - constituição progressiva da Geografia como disciplina escolar e científica, de um lado, e o desenvolvimento dos desafios locais, de outro - contribui para modificar o olhar dos geógrafos sobre o recorte territorial da França. Por sua vez, o discurso que eles elaboram irá repercutir sobre o debate.

Desconfiança para com as divisões administrativas, fim aos excessos mnemônicos, elogio ao raciocínio: viva a região natural, prega o artigo de 1888 . Depois da Revolução, a geografia se tornara pedagogia de um novo recorte: o departamento. A partir dos anos de 1870 , a renovação da geografia é acompanhada de uma crítica às divisões administrativas e da invocação sistemática do princípio naturalista, que consiste em rejeitar a característica convencional ou arbitrária de tais divisões e substitui-las pelo critério natural — o que significa, segundo os autores, conformidade às leis físicas da natureza, ou à história, ou aos interesses dos habitantes...

Entre estes pedagogos, Vidal (e seus alunos normalistas) milita por uma geografia ambiciosa que articule o local e o geral. Ele participa com seriedade da opção naturalista, mobilizando sistematicamente as novas informações fornecidas por geólogos e botânicos, construindo-as sob o argumento da região natural. Esforçase também em superar exclusivamente a referência geológica para pensar aquilo que então ạinda não se chama "meio geográfico". Enfim, Vidal funda sua prática científica sobre a idéia de uma ultrapassagem da experiência popular pela ciência.

Justificando uma nova grade para a pedagogia geográfica, constrói também quadros novos para a investigação científica. É este quadro regional que seus 
alunos vão recuperar em suas teses. Rapidamente desprovidas de a prioris metodológicos, as monografias regionais se justificam de diversas maneiras: estabelecer um inventário antes de generalizar; trabalhar sobre os espaços heterogêneos mas à medida de uma pesquisa individual; estudar as variações concomitantes dos fenômenos ou, o mais recorrente, resgatar a "personalidade" de uma individualidade geográfica. Em cada caso, a parte relativa à natureza é um meio de se distinguir em relação a outras abordagens regionais - seja da história clássica das formações políticas, seja de uma história das psicologias regionais $a$ la Michelet ou mesmo, na dependência da mutante moda regionalista tão cara à Belle Époque, dos inúmeros estudos locais conduzidos sem método.

De maneira geral, a análise feita por Vidal dos modos de recorte do espaço (e com ele a equipe dos Annales de géographie, revista criada em 1891) participa de um modo de legitimação da posição social dos geógrafos universitários. Ela tem como função principal conferir-lhes uma autonomia em relação às disciplinas vizinhas — notadamente a História, de onde ela provém, e a Geografia tradicional. O apoio demandado à Geologia e, posteriormente, à Ecologia, servem a esta legitimação junto à esfera do saber. Ao mesmo tempo, o modelo naturalista é o fundamento de uma racionalidade que concede determinada autoridade fora da Universidade.

\section{Regionalização e Regionalismo}

Efetivamente, este é o efeito do acesso à positividade científica com que a geografia universitária pode contar na virada para o século XX. O fato de estabelecer seu objeto, a divisão natural ou antes mesmo "geográfica", em oposição às circunscrições administrativas submetidas então à forte crítica da opinião, situa os geógrafos na posição de experts no debate político. Esta evolução é consumada em uma quinzena de anos. Enquanto os primeiros escritos de Vidal se voltam para um projeto pedagógico e científico voluntariamente distante das preocupações políticas do momento, ele é progressivamente apanhado pelo debate e envolvido, em parte a despeito dele, pela expertise ${ }^{7}$ social.

Desde 1903, a recepção feita ao Tableau mostra que a obra foi recebida na atualidade dos desafios contemporâneos, posto que as resenhas viam nela um apelo à descentralização. É um momento chave onde o grande público descobre ao mesmo tempo o sábio e o escritor que exalta o gênio nacional. É também o momento onde os círculos regionalistas apóiam-se em seu trabalho para legitimar sua ação propagandista: o Tableau é recebido em 1904 pela Federação Regionalista - a jovem organização transpartidária nascida em 1900 - como o "breviário do regionalismo". Em seis anos, Vidal torna-se o geógrafo expert em matéria de

\footnotetext{
${ }^{7}$. Segundo o Novo Dicionário Aurélio. palavra de origem francesa significando "perícia, avaliação ou comprovação realizada por experto". (N.T.)
} 
regionalização. Primeiro, ele é consultado ao lado de Pierre Foncin (1841-1916), geógrafo engajado de chofre na sinergia ciência-política e, portanto, autor de obras sobre a reorganização das circunscrições administrativas. Depois, Vidal parece afastar-se dessa posição, em virtude da dupla autoridade que lhe é atribuída: a de sábio rigoroso e a de chefe de escola. Quer dizer, um representante autorizado de toda uma rede de geógrafos especialistas, intervindo segundo os mesmos métodos na questão regional. Mais do que apenas a Vidal, é ao conjunto das monografias regionais que se reporta a Ação Regionalista, orgão da Federação Regionalista.

A partir de 1910, não é mais o Vidal do Tableau que serve de referência a este regionalismo, mas aquele das Régions Françaises, consultado (depois de sua intervenção sobre Régions naturelles e noms de pays de Gallois) por Charles Benoist, seu colega da Academia de Ciências Morais e Políticas, para a descentralização prometida por A. Briand pelo seu discurso de Saint-Chamond. Vidal figura, em julho de 1911, ao lado dos deputados Charles Beauquier e Louis Marin, como o principal expert em regionalização do Congresso das Sociedades de Geografia em Roubaix. Se o papel jogado pelas cidades é discutido, se a alternativa entre um recorte único e uma divisão flexível adaptada a cada um dos interesses em jogo suscita ainda maior discussão, a unanimidade se faz sobre uma moção consensual: a geografia deve ser consultada no que tange à questão regional. Durante a guerra, a primeira forma de regionalização asssumida na França é inspirada nos recortes de Vidal de la Blache, através do historiador Henri Hauser: trata-se do reagrupamento das Câmaras de Comércio em 20 regiões econômicas, instituídas pelo ministro Clémentel.

Uma análise das relações concretas, estabelecidas no curso dos anos 19041924, mostra que a escola de geografia representada por Vidal é consultada pela ala modernista do regionalismo. Ela não destaca nem o regionalismo cultural nem o regionalismo contra-revolucionário à la Maurras, mas um movimento econômico e político que se recruta na província junto aos atores econômicos mobilizados nos novos agrupamentos de que Vidal faz eco em 1910 e em 1917. São estes mesmos atores, reagrupados, por exemplo, nas Câmaras de Comércio da França industrial e nas associações pela promoção das vias navegáveis, que alguns raros "geógrafosprofissionais" aconselham então às cidades de Nantes, Nancy, Roubaix, Caen e, mais tarde, Grenoble. São estes mesmos "geógrafos-profissionais", intelectuais de um novo gênero, que encontramos na publicação da Escola de Altos Estudos Sociais em que Vidal (1911-1913) fez a introdução com a idéia da relatividade das divisões regionais. São eles: Louis Laffitte, promotor da associação "O Loire Navegável", depois secretário geral da Câmara de Comércio de Nancy; Jacques Levainville, industrial especialista de minas de ferro e de transportes; e Paul de Rousiers, de origem leplaysiana, especialista em portos europeus — todos os três bem inseridos nos Annales de Géographie.

De fato, com o protótipo da região polarizada configurado pela região lionesa, 
o Tableau faz a transição através da hesitação sobretudo entre a nostalgia do terroir $^{\natural}$ que desaparecia e a aspiração por uma nova França - ambigüidade que autoriza esta forma de Vidal de la Blache captar o século. Mas não observamos em suas cadernetas, em 1899-1900, a expressão "A França no limiar de novos tempos"? Em 1904, sua viagem através da América do Norte constitui um encontro decisivo com o americanismo, uma experiência existencial que pôde fazê-lo aspirar a uma escola do Novo Mundo.

Há muita distância entre o Vidal modernizador e o Vidal simpatizante dos "pays" que nele vemos frequientemente. Quanto à sua dualidade, está longe de ser convincente, posto que é nesta transição em direção ao modernismo que ele se situa por todo o início do século. Por qual estranho processo estas anamorfoses puderam ser produzidas? Como foram orientadas as avaliações contraditórias de Vidal de la Blache durante o século XX? Pelos mitos que acompanham toda idéia da fundação, pela decantação corporativa que a transmissão da profissão de geógrafo produziu e pelos modelos ideológicos que uma disciplina também engajada na função escolar interiorizou. Somente duas vias serão indicadas aqui. A primeira remete à evolução de uma disciplina científica, com suas fases de emergência, de "ciência normal" onde os gestos da profissão se consolidam, e os momentos de contestação do paradigma. Uma segunda via relaciona-se ao referente principal: a França e sua organização socio-política, a França e sua grandeza. Mas uma e outra não variam sincronicamente, e as interações nutridas entre estas duas lógicas e entre as redes de atores que as conduzem em diversos momentos são mal conhecidas.

Que a rotinização ${ }^{9}$ da profissão de geógrafo tenha sido operada desde o início deste século, antes mesmo da Grande Guerra, parece certo. Mas os desafios de uma reestruturação político-econômica da França estão então bastante vivos para que, mesmo após a guerra, a obra de Vidal seja lida no sentido de um diagnóstico para a ação. Sem dúvida que a conjunção da morte do "patrono" com a vitória e com os esforços derecuperação nacional dramatizaram esta leitura. Ao contrário, as debilidades do entre-guerras produzem uma involução em direção a uma ciência mais "fria", e a crise dos anos trinta ainda recai sobre a pesquisa em ciência social (como sobre uma grande parte do país) em direção a um local mitificado e folclorizado. Não é este o momento onde o pai fundador é embalsamado, confinado ao "localismo" e ao "ruralismo"? A não ser que alimentasse nostalgicamente a celebração daquilo que havia acabado, seu Tableau se reduzia a uma compilação de trechos escolhidos. Virá a Liberação, depois os

\footnotetext{
${ }^{8}$. Termo de difícil tradução, que pode às vezes aparecer como sinônimo de "pays". Segundo o Dicionário Larousse da língua francesa, entre outras definições, terroir, tal como utilizado a partir do século XIX, refere-se a "província, campanha considerada como o refúgio de hábitos, de gostos tipicamente rurais ou regionais". Tem muita relação com as aptidões agrícolas do solo.
}

9 "Routinisation", no original (N.T.). 
Trinta Gloriosos e o triunfo de uma modernidade técnica permanecendo como pano de fundo o Hexágono. Que valor tem então o fundador? A regionalização político-administrativa renasce desconfiando de um de seus teóricos - segundo um processo de amnésia também conhecido no urbanismo. Sobrevêm novas formas dessa modernização que, ao lado de outros geógrafos do século XX, Vidal de la Blache percebia como desafios para a França de amanhã. O debate pode ser retomado. Que futuro aguarda os novos encontros entre a Geografia e a política?

\section{ANEXO I - FRAGMENTOS DE TEXTOS DE PAUL VIDAL DE LA BLACHE ${ }^{10}$}

\section{Régions françaises \\ [Regiões Francesas]}

1910, pp. 839-842

Propositalmente, insistimos sobre o papel da cidade. Tal como a examinamos nestes exemplos, ela é o centro da ação. Sob uma nova forma, dá sequência a seu papel histórico nas formações políticas. Cidades e rotas são as grandes propulsoras da unidade: elas criam a solidariedade das regiões ${ }^{\prime \prime}$. Nossas mais antigas e duráveis divisões políticas não foram fundadas sobre a velha cidade galo-romana? Nas condições econômicas do mundo atual, este papel se precisa e se define. Não mais pelo número de habitantes, nem tampouco pelo de funcionários do Estado: nem mesmo toda forma de trabalho indistintamente constitui este tipo de cidade regional. É o elemento superior que se introduz por meio dela nas diversas formas de atividade. Ela desempenha a função de guia. Ela 'irriga' seguindo a expressão americana - a região [contrée] com seus capitais. (...) A cidade regional oferece as vantagens de uma organização já experimentada e uma ampla base de operações, de instituições, enfim, que somente ela possui capacidade de criar e de fazer funcionar. Conhece de perto e examina as empreitadas que subvenciona.

Assim, a cidade representa uma dessas nodalidades de ordem superior, servindo de intermediária entre a região [contrées] que elas valorizam e os mercados do exterior. Tal papel exige um conjunto de condições geográficas, e mesmo históricas, que se encontram reunidas apenas em certos pontos. Há sítios que

\footnotetext{
${ }^{10}$ Optamos, por questões meramente formais, colocar os extratos de textos (anexo I) e os mapas (anexo II) de Vidal de la Blache em anexo, numerados, ao final. No artigo original eles aparecem entremeados em distintos momentos do texto.

11 "contrées", que também traduzimos em outras passagens como "zonas". Sempre que traduzimos "contrée" como "região", optamos por manter o termo original entre colchetes, pois muitas vezes La Blache utiliza explicitamente o termo "région". (N. T.)
} 
puderam dar origem a importantes desenvolvimentos urbanos sem preencherem estas condições: Le Havre e Brest são demasiado exteriores, e cidades como Saint-Etienne e Montluçon são muito especializadas em certos gêneros de trabalho. Os sítios naturalmente designados são centros há muito tempo frequientados pelo comércio (...). Seu lugar foi preparado nas encruzilhadas dos Alpes, sobre nossos estuários fluviais, nos cruzamentos das vias dos Pirineus, na periferia do Maciço Central, no limiar dos Países Baixos. E assim sucessivamente, ao longo das vias trilhadas há muito tempo pelos homens. (...)

Desejaríamos uma organização propícia a este gênero de cidades, que, na França, aguarda, sem dúvida, apenas um sinal para se desenvolver, visto que a centralização não os impediu de nascer. Elas representariam o nível intermediário, mais necessário do que nunca, entre a cidade puramente local e a capital política demasiado distante. (...) Seria inexato, e mesmo absurdo, fazer abstração de Paris, em sua função distributiva de crédito, de iniciativa, de progresso técnico e de relações mundiais. (...) Paris é uma personagem considerável, cujos apetites são tão exigentes e cuja atração se estende tão longe, que é difícil, para ela, fazer a parte da função regional. (...) Na realidade, a atração parisiense encontra seus limites na atração das regiões vizinhas, e termina precisamente no ponto onde as forças concorrentes se equilibram. Os limites correm o risco de se tornar flutuantes apenas no momento em que a intensidade de um dos centros rivais venha a decrescer.

\section{La relativité des divisions régionales [A relatividade das divisões regionais]}

$$
1911 \text { (1913, pp. 8-12) }
$$

Nestes agrupamentos de outrora, estradas, mercados, burgos e cidades combinam-se de forma a responder às exigências de regiões [contrées] que procuram a auto-suficiência, viver por sua própria conta empregando o mínimo possível do exterior. A repartição das cidades obedece a uma espécie de ritmo regido sobre as comodidades da circulação; ela corresponde, mais ou menos, às distâncias possíveis de transpor com os meios de então - ida e volta, em um dia. A menos que estejam separadas respectivamente por 30,40 ou 50 quilômetros, não parece que muitas realidades urbanas possam subsistir com facilidade. Além disso, de acordo com o raio que abrangem, as cidades se mantêm em proporções medíocres. (...) Tais eram as condições nas quais a Assembléia Constituinte traçava suas divisões administrativas. Os novos quadros adaptavam-se ao estado econômico e aos meios de circulação da época. Capitais de departamentos e de arrondissements $^{12}$ estão ali dispostas como peças em um tabuleiro, em distâncias convenientes, cada uma com seu raio limitado de ação.

Mas eis a era das estradas de ferro. No início e durante muito tempo, não 
avaliamos a magnitude da revolução que elas aportavam. (...) Pouco a pouco as redes se formam, se combinam e se estendem. (...) [Extensão, concentração, urbanização, especialização, regiões de cidades especializadas]. Este fenômeno de concentração possui ainda uma outra forma de manifestação geográfica. Ele permite que muitas cidades coexistam sem se prejudicar, a favor da especialização do trabalho, sobre os mesmos lugares em que são reunidos os elementos de uma vida intensa. Diferenciando-se umas das outras pela variedade de produção às quais se dedicam, elas encontram vantagem ao tirar proveito comum das facilidades de crédito, de relações, de transporte e de mão de obra, e, conseqüentemente, as distâncias entre elas diminuem. (...) Antigamente, era a tendência inversa que prevalecia. De posse de um gênero de indústria, cada cidade não procuraria outra coisa senão impedir a aglomeração ${ }^{13} \mathrm{em}$ seu entorno, visando suprimir todo germe rival. Hoje, a nodalidade, entendendo esta nova expressão como a reunião de todos os auxiliares demandados pela vida comercial e industrial, tem vantagem sobre todas as outras considerações; é ela que, em certas regiões [contrées] propícias, atrai as cidades umas em direção às outras, como vemos as plantas reunidas em colônias sobre um pedaço de solo favorável (...) Submetidas, assim, como todas as coisas, às leis da evolução, as divisões regionais se fazem e se recriam segundo as mudanças produzidas nas relações entre os homens.

\section{Des divisions fondamentales du sol français [As divisões fundamentais do solo francês]} I888 (1897, pp. XIII-XIV)

Temos apenas que observar ao nosso redor para encontrar exemplos de divisões naturais. [Os nomes dos pays] sendo produtos da observação local, não conseguiriam abranger grandes extensões; são restritos como o horizonte daqueles que os utilizam. Antes de serem regiões, são pays. (...) A expressão pays tem a característica de se aplicar quase tanto aos habitantes quanto ao solo. [Os nomes de pays] exprimem não uma simples particularidade, mas um conjunto de aspectos extraídos ao mesmo tempo do solo, das águas, das culturas e dos modos de habitação. Eis, portanto, reproduzido fielmente, este encadeamento de relações, partindo do solo até chegar ao homem. Falávamos disso no começo como algo que deveria formar o objeto próprio do estudo geográfico! Instintivamente descoberto pela observação popular, este encadeamento se precisa e se coordena através da observação científica. (...) Com efeito, não recomendamos a aplicação direta. (...) Em um ensino voltado aos alunos, o estudo do solo fragmentar-se-ia para além da

\footnotetext{
${ }^{12}$ Circunscrição administrativa, distrito, bairro (N.T.).

13 "essaimer", enxamear, no original. (N.T.)
} 
medida admissível e, na análise muito fragmentária do detalhe, as relações gerais correriam o risco de desaparecer. (...) Em suma, sobre o quê estas divisões dos pays são fundadas? Elas resumem um conjunto de fenômenos que dependem quase sempre da constituição geológica do solo. De fato, a Geologia e a Geografia são duas ciências distintas, mas que se tocam de forma muito próxima.

\section{La géographie politique. A propos des écrits de M. Frédéric Ratzel [A geografia política. A propósito dos escritos do Sr. Frédéric Ratzel]} 1898, p. 110

A posição das cidades, sua importância recíproca e as próprias dimensões dos impérios se estabelecem em harmonia com um certo estado dos meios de comunicação e de transporte. (...) A rede das cidades era composta lentamente, em harmonia com os meios de comunicação de outrora: os de hoje, pela supressão de etapas que se tornaram sem objeto e pela acumulação de recursos que eles concentram em alguns pontos, presidem um novo modo de agrupamento das populações.

\section{Tableau de la géographie de la France [Quadro da geografia da França]}

1903, p.384-385

A história da antiga França desenvolveu-se durante um período onde as relações entre o poderio humano e os obstáculos de lentidão e de distância eram muito diferentes de hoje. Os meios que permitem que os produtos sejam transportados, em massa e regularmente, de uma parte da terra a outra, não existiam. Também era difícil, para qualquer pessoa, imaginar que uma região [contrée] pudesse confiar o cuidado de nutrir seus habitantes a uma região [contrée] afastada. (...) Nesta situação, a estima e a confiança estão exclusivamente na terra. (...) Uma região [contrée] - a França menos que qualquer outra - não vive somente de sua própria vida: ela participa de uma vida mais geral que a penetra, e a penetração destas relações gerais não pode senão aumentar com a própria civilização. Assim que se produzem grandes revoluções econômicas, como aquelas que as descobertas do século XIX trouxeram com os meios de transporte, quais habitantes do globo poderiam orgulhar-se de escapar às suas consequiências? Elas atingem tanto a cabana do camponês quanto a mansarda ${ }^{14}$ do operário, e repercutem nos salários, na venda dos produtos do solo e na duração das ocupações rurais. A natureza de tais transformações produzem consequências que o espírito humano, dificilmente, pode medir.

\footnotetext{
${ }^{14}$ Morada miserável, segundo o Novo Aurélio (N.T.).
} 


\section{Régions naturelles et noms de pays [Regiões naturais e nomes de países]} $1909(1910$, p.126-127)

Nossos grandes centros industriais engendram relações cuja trama se estende sem cessar e cobre de malhas cada vez mais cerradas as regiões circunvizinhas. (...) Se o movimento de concentração da grande indústria continua no mesmo passo após um quarto de século, o papel das cidades nas formações políticas só fez aumentar. Nesse caso, é a cidade que agrupa o território. O feixe de interesses que se prende em torno desses centros de capitais, de impulsão e de atividades diversas, exerce sobre as relações humanas uma influência que parece mais imperiosa que o liame tradicional representado pelo nome do pays. Ligação que se torna um pouco intermitente em meio aos movimentos múltiplos que, hoje, tendem a arrancar os homens de suas terras natais.

\section{La rénovation de la vie régional}

[A renovação da vida regional]

1917a, p.105-106

Este conjunto (o Norte) não representa uma província no sentido próprio do termo, mas é uma região econômica não menos sólida do que poderiam ser personalidades históricas de outrora. (...) ainda que se trate de região, não é preciso exagerar em procurar limites. É necessário conceber a região como uma espécie de auréola que se estende sem limites bem determinados, que encerra e que avança.

\section{La France de l'Est. Lorraine-Alsace}

\section{[A França do Leste: Lorena-Alsácia]}

$$
1917 \text { b, p. } 163
$$

Em seu prodigioso crescimento, a indústria moderna impulsiona tantas relações e suscita uma complexidade tal de negócios e de interesses, que ela não deixaria flutuar ao acaso as decisões cotidianas exigidas pelo estado do mercado e pelos conflitos de concorrência. Desde que o mecanismo assumiu um determinado crescimento, impõe-se a necessidade de um órgão diretor, como é o caso da Lorena, onde as questões de abastecimento de matérias-primas e de extração de seus produtos tornam-se, cada dia, mais imperiosas (...) Compreende-se que estas funções diretrizes têm seu lugar marcado na vizinhança imediata e, quando possível, no próprio centro do agrupamento ao qual elas se aplicam. As mil ligações que se dão entre participantes do trabalho comum, as relações de negócios e o conhecimento íntimo dos homens e das coisas só podem acomodar-se a este preço. A idéia regional é, sob sua forma moderna, uma concepção da indústria; ela se associa à idéia de metrópole industrial. 


\section{ANEXO II - MAPAS}

Mapa I. O recorte da França do "Tableau de la géographie de la France" de P. Vidal de la Blache, segundo a organização da parte descritiva do livro (conforme D. Loi, "Épistemologie et histoire de la géographie") (na legenda: divisões de primeira, segunda e terceira ordem)

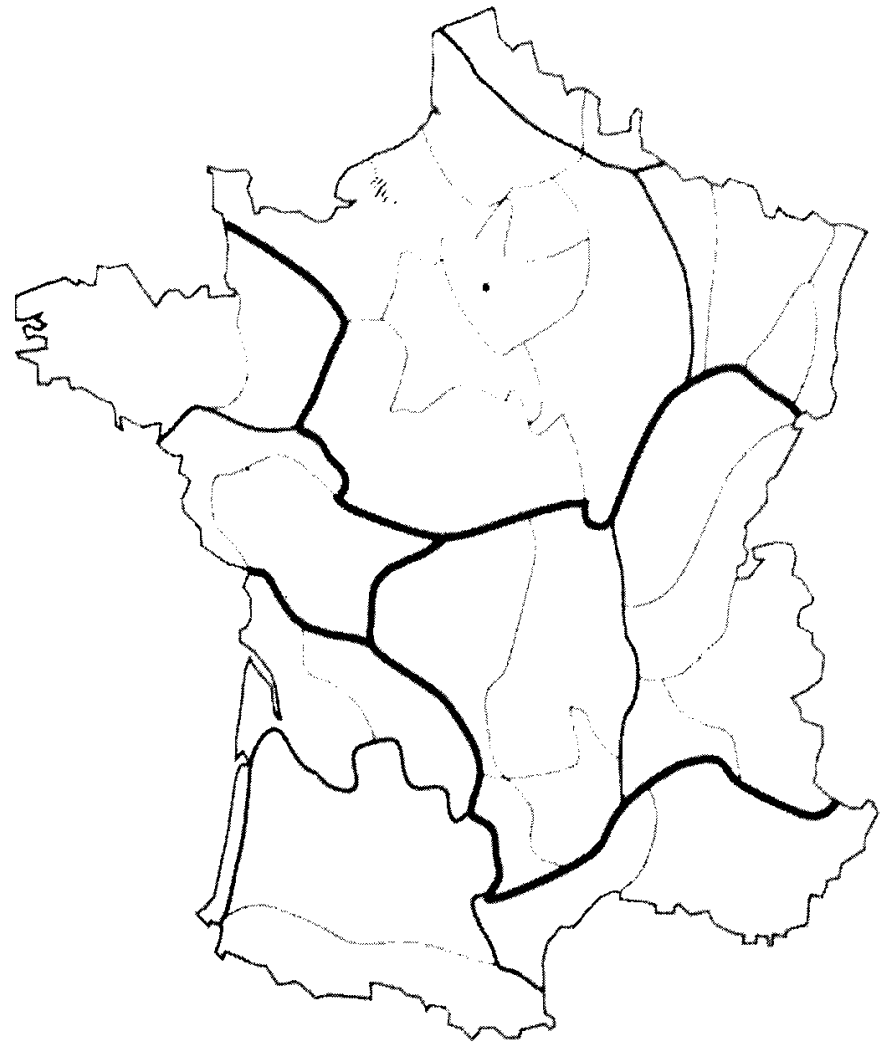



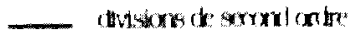

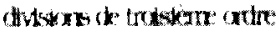

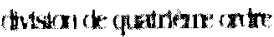


A França no limiar de novos tempos: Paul Vidal de La Blache e a Regionalização

Mapa 2. Ensaio de Agrupamentos Regionais de P. Vidal de la Blache em "Régions françaises", 1910. (na legenda: limites de regiões e limites de departamentos)

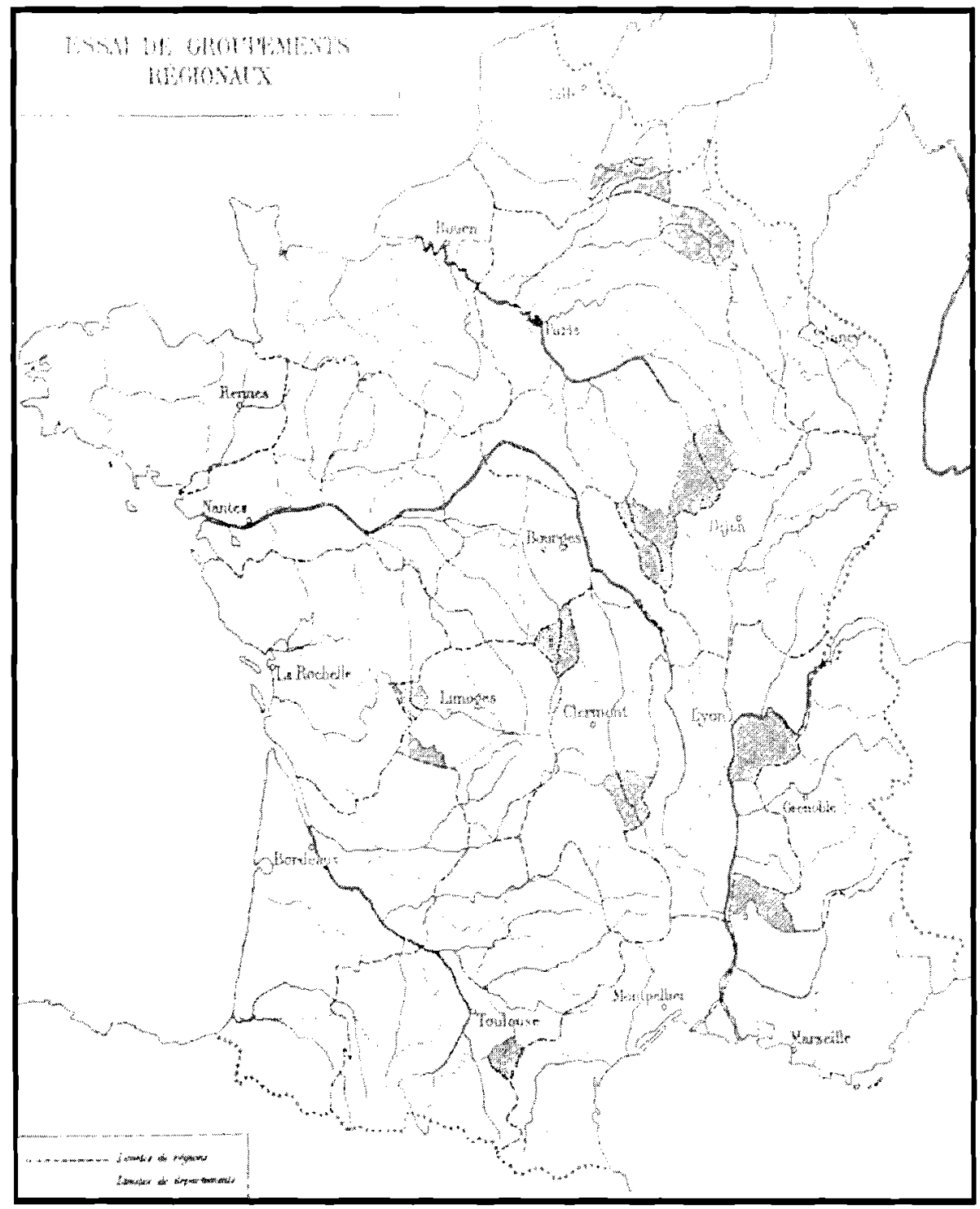


Resumo: No âmbito da renovação dos estudos sobre a história do pensamento geográfico, este artigo se opõe às interpretações que consagraram Paul Vidal de la Blache como um intelectual restrito às relações homem-meio e nostálgico da França camponesa. Uma leitura mais atent valiando a dinâmica sócio-econômica e seus impactos espaciais, a contribuição de Vidal de la Blache propunha, como solução para o futuro da França, uma nova regionalização do território nacional.

Palavras-chave: Pensamento Geográfico - Região - Regionalização - Território francês Pays.

\section{FRANCE ON THE EDGE OF NEW TIMES: PAUL VIDAL DE LA BLACHE AND REGIONALIZATION}

Abstract: This article presents a new perspective in the history of geographic thought, by opposing established approaches to Paul Vidal de la Blache as an intelectual restrict to relations man-environment and as a nostalgic of peasant France. A deeper reading of his work reveals a progressive passage from an initial "naturalistic" view to a socio-economic and urban-industrial approach. Through these economic impacts, Vidal proposes, as a solution for the future of France, a new regionalization of national territory.

Keywords: Geographic Thought - Region - Regionalization - French territory - Pays

\section{BIBLIOGRAFIA}

\section{Principais referências de Vidal de la Blache neste artigo}

Textos de Vidal de la Blache: dois livros aqui indicados foram recentemente reeditados, assim como alguns artigos (estes, porém, com alguns eventuais cortes). Eles aparecem marcados com um asterisco quando republicados em Sanguin (1993) e com dois quando republicados em Pinchemel et al. (1984).

* VIDAL DE LA BLACHE, Paul. Des divisions fondamentales du sol français. Bulletin littéraire (Journal de l'enseignement secondaire spécial, de l'enseignement secondaire des jeunes filles, de l'enseignement des langues vivantes, de l'enseigenement primaire supérieure), out,-nov., p.1-7 e p.49-57 (1888). (Reproduzido, a partir de 1897, como «Introdução » ao manual de primário de $\mathrm{P}$. CAMENA D'ALMEIDA e P. VIDAL DE LA BLACHE [La France. Cours de géographie à l'usage de l'enseignement secondaire. Paris: Armand Colin]).

(1895). Atlas Général Vidal-Lablache. Paris: Armand Colin.

(1898) La géographie politique. A propos des écrits de M. Frédéric Ratzel. Annales de Géographie, n. 32, mar., pp.97-111.

(1903) Tableau de la géographie de la France. Paris: Hachette. (Tomo 1, Primeira parte de LAVISSE, Ernst. Histoire de France depuis les origines jusqu'à la Révolution). (reedições recentes: 1979, prefácio de Paul Claval, Paris: Talandier; 1995, prefácio de Pierre George, Paris: La Table Ronde).

(1904) Les pays de France. La Réforme sociale, 48, pp.333-344. 
(1909) Régions naturelles et noms de pays. Journal des Savants, set.out., pp.389-401. (republicado em Comptes rendus, Séances et travaux de l'Academiedes Sciences morales et politiques, pp. 101-128 [1910]).

*__ (1910) Régions françaises. Revue de Paris, dez., pp. 821-849.

**__ (1911) La relativité des divisions régionales. Athéna, Conférence à l'École des hautes études sociales. (republicado como "Introdução" em Les divisions régionales de la France. Paris : Félix Alcan [1913]).

(1913) Intervention au Congrès national des Sociétés françaises de Géographie, sur la question du remaniement des régions administratives. Congrès national des Sociétés françaises de Géographie, $30^{e}$ session, Roubaix, juilletaoût 1911. Lille : Impr. L. Danel, pp.31-45.

(1917) La rénovation de la vie régionale. Foi et Vie: Les questions du temps présent, Cahier B, n.9, mai, pp. 103-110.

VIDAL DE LA BLACHE, P. (1917b) La France de l'Est: Lorraine-Alsace. Paris: A. Colin: X-280 p. (reedição: 1994, prefácio de Y. Lacoste. Paris: La Découverte, Livres Hérodote, XXXVIII, 285 p.)

\section{Trabalhos contemporâneos}

JUILLARD, Étienne (1962) La région, essai de définition. Annales de Géographie.

BERDOULAY, Vincent (1981) La formation de l'École française de géographie (1870-1914). Paris: Bibliothèque nationale.

CHAMBOREDON, Jean-Claude (1988) Cartes, désignations territoriales, sens commun géographique: les "noms de pays" de Lucien Gallois. Études rurales, 109.

CHARTIER, Roger (1992) La ligne Saint-Malo-Genève. In: NORA, Pierre (ed.). Les Lieux de Mémoire. III: Les France. 1. Conflits et partages. Paris: Gallimard.

CLAVAL, Paul, NARDY, Jean-Paul (1968) Pour le cinquantenaire de la mort de Paul Vidal de la Blache. Cahiers de géographie de Besançon, Paris: Les Belles Lettres, 16.

CLAVAL, Paul (1979 [1903]) Préface. In: VIDAL DE LA BLACHE, Paul. Tableau de la géographie de la France. Paris: Tallandier.

GEORGE, Pierre (1995 [1903]) Préface. In: VIDAL DE LA BLACHE, Paul. Tableau de la géographie de la France. Paris: La Table Ronde.

GUIOMAR, Jean-Yves (1993) Le "Tableau de la géographie de la France" de Vidal de la Blache. In: NORA, Pierre (ed). Les Lieux de Mémoire. II. La nation 2. Le territoire, l'état, le patrimonie. Paris: Gallimard. 
LACOSTE, Yves (1979) A bas Vidal... viva Vidal! Hérodote, 16.

(1994) Présentation de La France de l'Est. In: VIDAL DE LA BLACHE, Paul. La France de l'Est (Lorraine-Alsace). Paris: La Découverte, Livres Hérodote.

MEYNIER, Andre (1972) Histoire de la pensée géographique. Paris: PUF.

MUCHIELLI, L. (1994) Durkheim et la révolution des sciences humaines. La Récherche, set.

OZOUF-MARIGNIER, Marie-Vic (1992) Géographie et histoire. In: BAILLY, A., FERRAS, R., PUMAIN, D. (dir.). Encyclopédie de géographie. Paris: Economica.

(1995a) Les dimension du département: la permanence d'un débat. In: CHIANEA, G., CHAGNY, R., DEREYMEZ, J.-W. (ed.). Le département, hier, aujourd'hui, demain. De la province à la région. De la centralisation à la décentralisation. Grenoble: Presses universitaires de Grenoble.

(1995b) Les géographes et le découpage administratif de la France. Actes du Colloque "L'administration territoriale de la France (1750-1940)", Orléans, 30 set.-2 out. 1993.

ROBIC, Marie-Claire (1995) The Tableau is alive, and well... Reaction to the "Tableau de la géographie de la France" de Paul Vidal de la Blache. In: BUTTIMER, Anne (ed.). Text and image: constructing regional knowledges.

PETITIER, Paule (1993) Michelet géographe. L'information géographique, 57.

PINCHEMEL, Phillipe (1988) Contribution à l'histoire de la bibliographie sur P. Vidal de la Blache. In: PINCHEMEL, Phillipe (dir). Vidal de la Blache. Lectures et relectures. Bulletin des associations des géographes français, 4.

ROBIC, Marie-Claire (1984) TISSIER, Jean-Louis. Deux siècles de géographie française. Choix de textes. Paris: CTHS.

ROBIC, Marie-Claire (1982) Le pays et la défense du corps. Note à propos de "Régions naturelles et noms de pays". Géopoint 82. Les territoires de la vie quotidienne. Recherche de niveaux signifiants dans l'analyse géographique. Avignon, Groupe Dupont, Université de Genève, Université de Lausanne.

(1992) De la distribution à la disposition ou la France matricielle (sur Vidal de la Blache). Littérature et nation, $9,2^{\mathrm{e}}$ série.

(1993) L'invention de la "Géographie Humaine" au tournant des années 1900: les vidaliens et l'écologie. In: CLAVAL, Paul (dir.). Autour de Vidal de la Blache. La formation de l'école française de Géographie. Paris: Éditions du CNRS, coll. 
Mémoires et documents de géographie.

(1994) National identity in Vidal's “Tableau de la géographie de la France" : from political geography to human geography. In: HOOSON, David (ed.). Geography and national identity. Oxford: Blackwell.

(1996) Des vertus de la chaire à la tentation de l'action (et viceversa). Trajets de la géographie française de la Grande Guerre aux années cinquante. In: CLAVAL, Paul, SANGUIN, Andre-Louis (ed.). La Géographie française à l'époque classique (1918-1968). Paris: L'Harmattan.

SANGUIN, Andre-Louis (1993) Vidal de la Blache. Un génie de la géographie. Paris: Belin.

THIESSE, Anne-Marie (1991) Écrire la France. Le mouvement littéraire régionaliste de langue française entre la Belle Époque et la Libération. Paris: PUF.

TISSIER, Jean-Louis et al. (1988) Lyon et ses possibles: la région lyonnaise dans le "Tableau de la géographie de la France" de Paul Vidal de la Blache. Actes du $112^{e}$ Congrès national des Sociétés savantes, Lyon, 1987, Géographie (Milieux, villes et régions). Paris: CTHS.

VEITL, P. (1993) Un géographe engagé. Raoul Blachard en Grenoble. Genèses, 13. 